\section{Taking flight}

Stephen Hancocks OBE

Editor-in-Chief
Send your comments to the

Editor-in-Chief,

British Dental Journal

64 Wimpole Street,

London,

W1G 8YS

Email bdj@bda.org
As regular readers cannot have failed to noticed, the series of images on the front covers of the current volume of the $B D J$ are pictures created by school children in Wales who took part in the Welsh government's Designed to Smile oral health improvement programme. We were delighted to be approached to participate in this way and, apart from good oral health, the result has been not only a delightful and cheering set of covers but also a huge boost to the individual artists and their schools who have all benefitted from the books provided by the journal and Nature Publishing Group as the prizes. Additionally, the drawings and $B D J$ covers are to feature in a public display in the Senedd, the Welsh government building, between 22 January and 14 February 2014.

The combination of Christmas and our young illustrators reminded me of a television item many years ago when a boy was explaining his illustration of an airplane as relevant to the seasonal story. Visible in the plane's windows were a man and a woman holding a baby, whilst another man was waving from the cockpit. 'How is this to do with the nativity?' asked the tv presenter. 'Well,' explained the earnest youngster, 'it's the flight out of Egypt with Joseph, Mary and her baby and that's Pontius the Pilot.'

\section{POINTING THE WAY}

Now, at this merry time of year I hope you might allow me this corniest of segue in an almost disc-jockey like way into the subject of pilots; and not the flying type. The first of the pilots for the next NHS dental contract have now been in progress since 2011, with a further 15 joining last year bringing the total to 90 .

The plan to date has been to trial various types of organisation of the new scheme or schemes in different practices with a view to bringing together the best parts of as many as possible into one new contract to be rolled out across England probably in, or for, 2015. However, it seems that there may be some movement on this sooner and there is a growing likelihood that next year could see at least a partial unveiling. While one would not wish to hurry the process unnecessarily, since a considered package of reform has to be better than the rushed and imposed settlement that became the current and generally agreed unfit for purpose process that produced the Unit of Dental Activity (UDA) debacle, when it happens the market will surely gasp a collective sigh of relief. By 'the market' I mean dentistry in general and the dental industry in particular. No market likes uncertainty. Whether one is buying and selling stocks, trading futures or dealing in commodities any lack of assurance about what is going to happen spreads conjecture, jiggers prices and warps investment decisions. People tend to sit on their hands. And for a dentist, sitting on his or her hands is not a route to a successful practice. Consequently, these last few years have bred confusion and uncertainty.

Once the details of the next contract are unveiled the most important aspect will be the way in which the remuneration is to be calculated. The American expression is to 'monetise' it and although this seems to me to be an irritating word it does express the process rather well. For be assured that this will enable practitioners to make their minds up and to make decisions based on this for the future of their practices, their teams and the structure of their teams.

However, there is one aspect that we do know in advance. There is to be no new money, no additional funds, no greater budget. The distribution will be different and the working patterns changed but the cash on the table remains the same. My guess is that it will divide three ways. Some dentists will embrace the new system and either continue with or take up NHS dental care. Others will assess the offering and decide either to use this as an opportunity to travel down the route of private dentistry or to throw in the towel, put the practice on the market and retire or quit in general. John Milne, Chair of the British Dental Association's (BDA's) General Dental Practice Committee (GDPC) recently stated that new contractual arrangements must work for practitioners and patients alike if confidence in the future of NHS dentistry in England is to be maintained. Whichever options are chosen and in whatever proportions at least we will all know how to take the next steps and my prediction is that it will open up a great deal of activity, excitement and a lot of fervent discussion. It will break the dreariness of the current impasse.

Irrespective of what 2014 brings in terms of new contracts and fresh prospects it gives me the very greatest of pleasure in taking the opportunity to thank all our readers for your continuing sincere support, robust feedback and generous consideration throughout this year. The whole team here at the $B D J$ join me in wishing you a very Merry Christmas and a Happy, Healthy and Prosperous New Year.

DOI: 10.1038/sj.bdj.2013.1194 